\title{
New species and taxonomic notes of scaly crickets (Orthoptera: Mogoplistidae) from Borneo
}

Running title: new scaly crickets from Borneo

\author{
MING KAI TAN ${ }^{1 *}$, RAZY JAPIR ${ }^{2}$, ARTHUR Y. C. CHUNG ${ }^{2}, \&$ RODZAY BIN HAJI ABDUL WAHAB ${ }^{3}$ \\ ${ }^{1}$ Institut de Systématique, Evolution et Biodiversité (ISYEB), Muséum national d'Histoire naturelle, CNRS, SU, \\ EPHE, UA, 57 rue Cuvier, CP 50, 75231 Paris Cedex 05, France. \\ MKT: orthoptera.mingkai@gmail.com; https://orcid.org/0000-0002-4324-6305 \\ ${ }^{2}$ Forest Research Centre (Sepilok), Sabah Forestry Department, P.O. Box 1407, 90715 Sandakan, Sabah. \\ RJ:Razy.Japir@sabah.gov.my \\ AYCC: Arthur.Chung@sabah.gov.my; https://orcid/org/0000-0002-9529-4114 \\ ${ }^{3}$ Institute for Biodiversity and Environmental Research, Universiti Brunei Darussalam, Jalan Universiti, BE1410, \\ Brunei Darussalam. \\ RW: rodzay.wahab@ubd.edu.bn; https://orcid/org/0000-0002-2151-7709
}

\begin{abstract}
Recent orthopteran surveys in the hyper-diverse Borneo, i.e., Brunei Darussalam and Sandakan in Sabah, allow us to review the scaly crickets from the subfamily Mogoplistinae there. We discover and describe the male, as well as formally naming Cycloptiloides bimaculata Tan, Razy \& Chung, sp. nov. from Sandakan. This species was previously described as sp. 1 in a comprehensive revision by Ingrisch (2006) but only the females were known. We also describe Ectatoderus nigrofasciatus Tan \& Wahab, sp. nov. from Brunei Darussalam. New locality records are reported for Apterornebius kinabalu Ingrisch, 2006 in Sandakan (Sabah) and Ornebius pullus Ingrisch, 2006 in Belait District (Brunei).
\end{abstract}

Key words: Cycloptiloides, Ectatoderus, Ornebius, Brunei Darussalam, Malaysia, Southeast Asia

\section{Introduction}

The subfamily Mogoplistinae Costa, 1855 are commonly called scaly crickets, since their body except for the wings is densely covered by scales that can be colourful in some species (e.g., Ornebius Guérin-Méneville, 1844) or merely of dull or black colour (e.g., Cycloptiloides Sjöstedt, 1910). Species of Mogoplistinae can live in the canopy (e.g., two species of Ornebius were found to be the dominant species of Orthoptera of the canopy fauna in the Kinabalu area of Sabah [Floren et al. 2001]), while other species of the same genus live in the lower vegetation. Again other species (e.g., of Cycloptiloides) prefer to live on the ground where they can hide among leaf litter. The latter group contains the smallest species of the subfamily. Species living on foliage can be colourful. The Mogoplistinae from Southeast Asia have been studied sporadically (e.g., Ingrisch, 1998) before a comprehensive taxonomic revision was done by Ingrisch (2006). Since then, a few studies published new species from the region, including Malay Peninsula (Tan \& Ingrisch, 2013; Tan \& Kamaruddin, 2013; Tan, 2014), Thailand (Tan et al., 2015) and the Philippines (Tan et al., 2019).

Despite Borneo's rich biodiversity, relatively few scaly crickets are known from the island: 13 species in three genera according to Cigliano et al. (2021), most of them from Sabah. It is probably attributed to the lack of sampling and study of the species there. For example, only two Micrornebius Chopard, 1969 are currently known from Borneo: Micrornebius incertus (Ingrisch, 1998) and Micrornebius lineatus Ingrisch, 2006. In contrast, comprehensive samplings in a much smaller Singapore has led to the discovery of five congeners (Ingrisch, 2006; Tan \& Ingrisch, 2013; Tan, 2014). As many species have limited distribution, more intensive samplings, especially in unexplored parts of Borneo, are likely to yield new discoveries.

To address the knowledge gaps on Bornean Mogoplistinae, orthopteran surveys were conducted in Brunei Darussalam and Sabah by the authors. By amassing new specimens, the new species Cycloptiloides bimaculata Tan, Razy, Chung, sp. nov. are described from Sandakan and Ectatoderus nigrofasciatus Tan \& Wahab, sp. nov. from Belait District in Brunei Darussalam. New locality records are reported for Apterornebius kinabalu Ingrisch, 2006 in Sandakan in the east of Sabah, previously known from Kinabalu Range in the west of Sabah; and Ornebius pullus Ingrisch, 2006 in Belait District (Brunei), previously known from Brunei-Muara District. 


\section{Materials and Methods}

Opportunistic collection of crickets were done at Andulau Forest Reserve in Belait District (Brunei Darussalam) between 23 February and 3 March 2019 and between 6 and 9 July 2019, as well as the Rainforest Discovery Centre, Sepilok in Sandakan (East Malaysia: Sabah) between 8 and 12 January 2019. In-situ images were taken using a Canon EOS 500D digital SLR camera with a compact-macro lens EF $100 \mathrm{~mm} \mathrm{f} / 2.8 \mathrm{Macro}$ USM and Canon Macro Twin Lite MT-24EX was used for lighting and flash.

The specimens were preserved in absolute analytical-grade ethanol and later pinned and dry-preserved. A single hind leg from each specimen was also preserved in absolute analytical-grade ethanol for future molecular work. Male genitalia were dissected by squeezing the cerci against one another laterally, then cleaned using aqueous $\mathrm{KOH}$ and subsequently preserved in glycerine. Terminology used to describe the male genitalia follows Ingrisch (2006).

Images of habitus and morphological features were done using a Canon EOS 500D digital SLR camera with a macro photo lens MP-E $65 \mathrm{~mm} \mathrm{f} / 2.8 \mathrm{USM}(1-5 \times)$. Canon Macro Twin Lite MT-24EX was used for lighting and flash. Image editing was accomplished using Adobe Photoshop CC 2014 (Adobe Systems Incorporated, San Jose, CA, USA).

Measurements of specimen were made using ImageJ 1.51j8 (Wayne Rasband, Research Services Branch, National Institute of Mental Health, Bethesda, MD, USA). For the measurements, the following abbreviations are used: BL = body length; FRW = frontal rostrum width; $\mathrm{SW}=$ scapus width; $\mathrm{EW}=$ eye width; $\mathrm{PL}=$ pronotum length; $\mathrm{PW}=$ pronotum width; $\mathrm{TL}=$ tegmen length; $\mathrm{HFL}=$ hind femur length; $\mathrm{HFW}=$ hind femur width; $\mathrm{HTL}=$ hind tibia length; $\mathrm{HML}=$ hind metastarsus length.

Specimens were deposited in:

FRC Forest Research Centre (Sepilok), Sabah Forestry Department, East Malaysia

UBDM Universiti Brunei Darussalam Museum, Brunei Darussalam

ZRC Zoological Reference Collection, Lee Kong Chian Natural History Museum, Singapore

\section{Taxonomy part}

\section{Family Mogoplistidae Costa, 1855}

\section{Subfamily Mogoplistinae Costa, 1855}

\section{Genus Apterornebius Ingrisch, 2006}

Remarks. Since its erection, the genus consists of two species, A. chong Ingrisch, 2006 from Thailand and Singapore (Ingrisch, 2006; Tan, 2012, 2017) and A. kinabalu Ingrisch, 2006 from Borneo.

\section{Apterornebius kinabalu Ingrisch, 2006}

(Fig. 1)

Apterornebius kinabalu Ingrisch, 2006: 165

Material examined. 1 male (SDK.19.103) and 1 female (SDK.19.104), EAST MALAYSIA, Sandakan, Kabili Sepilok Forest Reserve, N5.87084, E117.93764, 98.7 \pm 6.1 m.a.s.l., mating on foliage, 3 October 2019, 2058h, coll. M. K. Tan \& J. L. Yukang (FRC).

Distribution. Borneo (Sabah: Sorinsim on Kinabalu, Sepilok in Sandakan)

Remarks. The specimens reported agree with the original description by Ingrisch (2006) in general habitus, maxillary palps, male abdominal apex, male phallic complex, female ovipositor (Fig. 1). The locality Sepilok is a new record for this species that was described and previously known only from Kinabalu. While Kinabalu is a mountainous terrain, Sandakan has a lower and flatter terrain.

\section{Cycloptiloides bimaculata Tan, Razy \& Chung, new species}

(Figs. 2-4) 
Micrornebius incertus (Ingrisch, 1998) - Ingrisch, 1998: 232 [one of the females (not a type) erroneous described under Derectaotus incertus]

Cycloptiloides sp. 1 - Ingrisch, 2006: 185

Material examined. Holotype, male (SDK.19.20), East Malaysia, Sabah, Sandakan, Sepilok, Rainforest Discovery Centre, N5.87580, E117.94299, 39.1 \pm 5.4 m.a.s.l., leaf litter, 9 January 2019, 1911h, coll. M. K. Tan, R. Japir, M. Binti, J. L. Yukang (FRC).

Paratypes, 2 females: 1 female (SDK.19.19), same locality, N5.87356, E117.94172, 49.1 \pm 5.2 m.a.s.l., leaf litter, 9 January 2019, 1105h, coll. M. K. Tan, R. Japir, M. Binti, J. L. Yukang; 1 female (SDK.19.35), same locality, N5.87553, E117.94116, 33.4 \pm 4.9 m.a.s.l., 9 January 2019, 2040h, coll. M. K. Tan, R. Japir, M. Binti, J. L. Yukang (all FRC).

Remarks. Ingrisch (2006) described the female of this species as Cycloptiloides sp. 1 without providing a species name. Here, we provide a formal name, assign a male holotype and describe the male.

Diagnosis. The male differs from congeners by the supra-anal plate trapezoidal in shape with apical margin broadly rounded, with dark scales and yellow brown setae laterally and shiny pale in the middle (forming two spots). The female differs from congeners by shorter maxillary palps and ovipositor and more transverse supraanal plate (Ingrisch, 2006).

Etymology. The species name refers to the two spots in the middle of the supra-anal plate; bi = two in Latin, maculata $=$ spotted in Latin .

Description. Habitus of male as shown in Figs. 2, 3. Dorsum of head flattened (Fig. 3A). Frontal rostrum 1.2 times wider than scapus. Maxillary palps with apical (= fifth) a little longer than subapical (= fourth) and third segments, subapical and third segments subequal lengths; apical segment little widened (Fig. 4A). Pronotum about 1.5 times longer than wide with anterior dorsal margin distinctly concave; lateral margin subparallel in anterior half and faintly widening posteriorly; covering tegmen entirely; posterior margin convex. Fore tibia with internal tympanum large and elongate oval (Fig. 4B); without external tympanum. Hind femur 1.4 times longer than hind tibia; hind tibia 2.1 times longer than hind metatarsus.

Male. Supra-anal plate trapezoidal with apical margin broadly rounded, with setae at lateral parts (Figs. 4C, 4D). Subgenital plate trapezoidal, posterior margin slightly convex (Fig. 4F). Epiphallus and phallic complex hyaline (Fig. 4E).

Female. Already sufficiently described in Ingrisch (2006). Our female specimens from Sandakan agree with the description.

Colouration. General colouration similar to female described in Ingrisch (2006). Male supra-anal plate with dark scales laterally, middle shining pale coloured (forming two spots) (Figs. 4C, 4D). Cercus (both male and females) with brown scales.

Measurements (in mm). Holotype $\mathrm{BL}=3.9 ; \mathrm{FRW}=0.27 ; \mathrm{SW}=0.14 ; \mathrm{EW}=0.14 ; \mathrm{PL}=1.9 ; \mathrm{PW}=1.3 ; \mathrm{HFL}$ $=2.5 ; \mathrm{HFW}=0.9 ; \mathrm{HTL}=1.8 ; \mathrm{HML}=0.8$.

Distribution. Borneo (Sabah: Kinabalu, Sandakan)

\section{Genus Ectatoderus Guérin-Méneville, 1847}

\section{List of Southeast Asian species:}

Ectatoderus angusticollis Chopard, 1969 from Singapore

Ectatoderus apterus (Chopard, 1925) from Java

Ectatoderus argentatus Ingrisch, 2006 from Thailand

Ectatoderus marginatus Bey-Bienko, 1966 from Lesser Sunda Islands

Ectatoderus pallidegeniculatus Brunner von Wattenwyl, 1893 from Myanmar [probably Micrornebius]

Ectatoderus samui Ingrisch, 2006 from Thailand

Ectatoderus sordidus (Walker, 1869) from New Guinea

\section{Ectatoderus nigrofasciatus Tan \& Wahab, new species}

(Figs. 5-7)

Material examined. Holotype, male (BRU.19.70), BRUNEI DARUSSALAM, Belait District, Jalan Labi near Andulau Forest Reserve, N4.63354, E114.51047, 76.6 55.0 m.a.s.l., on rattan foliage, 7 July 2019, 2042h, coll. M. K. Tan (UBDM). 
Diagnosis. The new species is characterised by the scapus being dorsally black but ventrally and laterally brown, and the antennae being wholly black; the head has a distinct black band behind eyes; and the male phallic complex has the medial valve elongated, not curved to a spiral, sinuous both dorso-ventrally and laterally and with the ventro-external sclerite of the lateral valve being elongated, in basal third broader, and tapering into a narrow lamella with subacute apex.

The new species is closest in distribution to E. angusticollis Chopard, 1969 from Singapore. In both species the pronotum is more strongly widening apicad, and fore and middle tibiae are provided with black dorsal stripes. The new species differs by the scapus and antennae being black instead of testaceous, by the head being provided with a distinct black band behind eyes and by the male phallic complex having the medial valve not curved to a spiral.

The new species is most similar to E. argentatus Ingrisch, 2006 from Thailand having the pronotum strongly widening apicad and the frons dark; it differs by the darked scapus and basal antennal segments instead of being yellow brown, by the male phallic complex which is more elongated and having the medial valve sinuous rather than curving upward (basally) and by the shape of the apical sclerotization of the medial valve.

Compared to species that have the pronotum moderately or strongly widening apicad, this new species differs from E. samui Ingrisch, 2006 from Thailand by the pronotum being more strongly widening apicad and by the male phallic complex having the medial valve not curved to a spiral; from E. marginatus Bey-Bienko, 1966 from Lesser Sunda Islands it differs by the pronotum being more strongly widening apicad.

Etymology. The species name refers to the black band posterior of eyes and the black scapus (dorsally only) and antennae; nigro = black in Latin, fascia $=$ band in Latin .

Description. Habitus of male as shown in Fig. 5. Dorsum of head flattened (Figs. 6A, 6B). Frontal rostrum 1.3 times wider than scapus (Fig. 6A). Maxillary palps with apical (= fifth) and subapical (= fourth) segments of subequal length, third segment longer than apical and subapical segments; apical segment triangular and widened apically (Fig. 6B). Pronotum about 1.7 times longer than wide with anterior dorsal margin narrow and straight; lateral margin widening posteriorly; strongly produced posteriorly and covering near-entirely tegmen; posterior margin convex. Fore tibia with internal tympanum small and oval; without external tympanum. Hind femur 1.1 times longer than hind tibia; hind tibia 4.4 times longer than hind metatarsus.

Male. Supra-anal plate with last abdominal tergite and epiproct distinctly separated by a transverse suture; last abdominal tergite transverse, with hind margin emarginate; supra-anal plate less transverse than last abdominal tergite, flattened, with fewer setae, apex rounded (Fig. 6E). Genitalia as in Fig. 7. Epiphallus elongated and membranous. Medial valve elongated, not curved to a spiral, sinuous both dorso-ventrally and laterally. Lateral valves weakly sclerotised, forming stout and truncated lobes at apex. Ventro-external sclerite of lateral valve elongate, basal third broader, tapering into a narrow lamella with subacute apex.

Female. Unknown.

Colouration. Head dorsum light brown, with white stripe running along lateral margin from posterior end, along inner margin of eyes to frontal rostrum (Figs. 6B, 6D). Scapus dorsally black, otherwise brown (Figs. 6A, 6D); basal antennal segments black, thereafter brown with some segments black (Figs. 6A, 6D). Frons and mouthparts dark coloured (Fig. 6C). Maxillary and labial palps yellow brown (Figs. 6B, 6C). Lateral parts of head, including genae, light brown, with a black horizontal band behind eyes. Pronotal dorsal disc brown, apical margin with white scales. Pronotal lateral lobes also with white scales and with brown margins (Fig. 6D). Tegmen mostly infumated white, but infumated grey at apical area of lateral field (Fig. 6D). Femur generally pale brown to medium? brown. Fore and middle tibiae dorsally black, otherwise brown. Tarsi with basal segment brown, with middle and apical segments black. Hind femur generally brown with knee dark. Hind tibia brown, dorsally pale yellow. Abdomen with tergites black covered with greyish brown scales; sternites black with whitish scales especially on those nearer to thorax. Abdominal apex black; last abdominal tergite back with brown setae along posterior margin (Fig. 6E). Cercus brown.

Measurements (in mm). Holotype $\mathrm{BL}=7.6 ; \mathrm{FRW}=0.28 ; \mathrm{SW}=0.22 ; \mathrm{EW}=0.26 ; \mathrm{PL}=3.9 ; \mathrm{PW}=2.2 ; \mathrm{TL}=$ $2.3 ; \mathrm{HFL}=4.3 ; \mathrm{HFW}=1.3 ; \mathrm{HTL}=4.0 ; \mathrm{HML}=0.9$.

Distribution. Borneo (Brunei Darussalam)

\section{Ectatoderus angusticollis Chopard, 1969}

Ectatoderus angusticollis Chopard, 1969: 193

Ectatoderus angusticollis - Tan, 2012: 58; Tan et al., 2015: 48; Tan, 2017: 57

Material examined (image). Holotype, male, SINGAPORE, coll. C. F. Baker (MNHN-EO-ENSIF4487).

Material examined. 2 males (F4.F.12, H12.F.05), SINGAPORE, Mandai, secondary forest between Mandai Road and Upper Seletar Reservoir, 16-26 November 2015, night, coll. M. K. Tan (ZRC); 2 males

(ZRC.ORT.467), SINGAPORE, Lower Pierce Reservoir Park, secondary forest, 10 August 2012, coll. M. K. Tan. 
Genus Ornebius Guérin-Méneville, 1844

Species group flori Ingrisch, 1998

Remarks. This species group currently consists of Ornebius fastus Yang \& Yen, 2001 from Taiwan, Ornebius flori Ingrisch, 1998 and Ornebius marginatus Ingrisch, 1998 from Sabah, Ornebius pullus Ingrisch, 2006 from Brunei, and Ornebius xinyao Tan, 2015 from Singapore. The species are characterised by the male phallic complex having the lateral valves membraneous, dorso-ventrally compressed and acute apically; internal sclerites of medial valve almost forming a tube and with apex of ejaculatory duct truncated and little notched (He et al., 2021).

Ornebius pullus Ingrisch, 2006

(Figs. 8-10)

Ornebius pullus Ingrisch, 2006: 157

Ornebius pullus - He et al., 2021: 88

Ornebius cf. pullus - Tan, 2012: 34; Tan \& Ingrisch, 2013: 25; Tan, 2017: 55; Tan, 2019: 335

Material examined. 1 male (BRU.19.13), BRUNEI DARUSSALAM, Belait District, Jalan Labi near Andulau Forest Reserve, N4.62238, E114.51047, 101.3 \pm 6.4 m.a.s.l., on foliage, 24 February 2019, 2052h, coll. M. K. Tan \& H. Yeo (ZRC); 1 male (BRU.19.74), BRUNEI DARUSSALAM, Belait District, Jalan Labi near Andulau Forest Reserve, N4.63352, E114.51061, 89.0 \pm 7.1 , on foliage, 8 July 2019, 2119h, coll. M. K. Tan (UBDM).

Other material examined. 1 male (D18.F.03), SINGAPORE, Mandai, secondary forest between Mandai Road and Upper Seletar Reservoir, 13 November 2015, night, coll. M. K. Tan (ZRC).

Remarks. The male specimens from Belait District agree with the original description of $O$. pullus (see Ingrisch, 2006) from Brunei-Muara District of Brunei Darussalam by habitus, size (Figs. 8, 9), shapes and colours of the epiproct and the paraproct process, as well as by the shape of phallic complex. However, the colour of the tegmen can be variable. While in one male (BRU.19.13) the colouration of the tegmen agrees with that of the holotype from Brunei-Muara, in the other male (BRU.19.74) the colour of the tegmen is somewhat intermediate between those of $O$. pullus and $O$. flori from Kinabalu in Sabah.

Tan \& Ingrisch (2013) previously noted that this species may have also occurred in Singapore, although there are some variations from the Bruneian specimens. Specifically, the apices of the membranous lateral valves of the male phallic complex can vary in their length and prominence and the tegmen colouration of the Singapore specimens is darker than those from Brunei (Fig. 10).

We postulate that $O$. pullus from Brunei and Singapore may either represent a species complex or a polymorphic species. Molecular phylogeny may be useful to resolve this problem.

Distribution. Within Brunei Darussalam, this species can be found in the western areas (i.e., Belait and Brunei-Muara Districts, it is probably also found in Tutong District between Belait and Brunei-Muara), but not in the eastern part of Brunei (i.e., Temburong District) (see Tan \& Wahab, 2018). One potential explanation is that O. pullus is found in the flatter terrains in Belait and Brunei-Maura Districts rather than the hilly terrains of Temburong District.

\section{Acknowledgements}

The authors are grateful of Sigfrid Ingrisch for providing references and markedly improving the manuscript. The authors are thankful to Huiqing Yeo (in Brunei Darussalam), Momin Binti, John Lee Yukang and Saudi Bintang (in Sandakan) for field assistance. The permissions for collecting and exporting material were granted by the Forestry Department, Ministry of Primary Resources and Tourism, Brunei Darussalam (JPH/PDK/01 Pt 2 and BioRIC/HOB/TAD/51-80 respectively) and the Sabah Biodiversity Centre (JKM/MBS.1000-2/3 JLD.3 (99)) (for Sandakan). MKT is thankful to Wendy Wang for permitting the examination of specimens in the ZRC. The work of MKT was supported by the Orthoptera Species File Grant 2019 under the taxonomic research project titled "Contribution to the species diversity and acoustic data on Orthoptera from Sandakan (Borneo, East Malaysia, Sabah)"; and Percy Sladen Memorial Fund (The Linnean Society of London) under the project titled "Advancing biodiversity informatics of Orthoptera from Brunei Darussalam".

\section{References}


Chopard, L. (1969) Family Gryllidae: Subfamilies Mogoplistinae, Myrecophilinae, Scleropterinae, Cachoplistinae, Pteroplistinae, Pentacentrinae, Phalangopsinae, Trigonidiinae, Eneopterinae; Family Oecanthidae, Gryllotalpidae. In: Beier, M. (Ed.), Orthopterorum Catalogus. Vol. 12. Uitgeverij Dr. W. Junk N. V.'s, Gravenhage, pp. 215-500.

Floren, A., Riede, K. \& Ingrisch, S. (2001). Diversity of Orthoptera from Bornean lowland rain forest trees. Ecotropica 7: 33-42.

Ingrisch, S. (1998) New Mogoplistinae from the Kinabalu region in Sabah, North Borneo (Insecta: Ensifera: Grylloidea: Mogoplistidae). Senckenbergiana Biologica, 77, 225-234.

Ingrisch, S. (2006) New taxa and notes on some previously described species of scaly crickets from South East Asia (Orthoptera, Grylloidea, Mogoplistidae, Mogoplistinae). Revue Suisse de Zoologie, 113 (1), 133-227. https://doi.org/10.5962/bhl.part.80345

He, Z., Ma, G. E., Long, J., Wang, Y., Zhang, T. \& Ma, L. (2021) Taxonomy of scaly crickets (Orthoptera: Mogoplistidae: Mogoplistinae) from China: five new species groups and three new species of the genus Ornebius Guérin-Méneville, 1844. Zootaxa, 4942 (1), 72-94. https://doi.org/10.11646/zootaxa.4942.1.3

Tan, M. K. (2012) Orthoptera in the Bukit Timah and Central Catchment Nature Reserves (Part 2): Suborder Ensifera. Raffles Museum of Biodiversity Research, National University Singapore, Singapore. 70 pp. Uploaded 14 November 2012.

Tan, M. K. (2014) New species of tiny scaly crickets of genus Micrornebius (Orthoptera: Mogoplistidae) from Singapore. Zootaxa, 3895 (1), 117-126. https://doi.org/10.11646/zootaxa.3895.1.7

Tan, M. K. (2017) Orthoptera in the Bukit Timah and Central Catchment Nature Reserves (Part 2): Suborder Ensifera. $2^{\text {nd }}$ Edition. Lee Kong Chian Natural History Museum, National University of Singapore, Singapore. 101 pages. Uploaded 16 June 2017.

Tan, M. K. (2019) Orthoptera species checklist of Bukit Timah Nature Reserve in the Zoological Reference Collection, Singapore. Gardens' Bulletin Singapore, 71 (Supplement 1), 331-338.

Tan, M. K., Dawwrueng, P. \& Artchawakom, T. (2015) Contribution to the taxonomy of scaly crickets (Orthoptera: Mogoplistidae: Mogoplistinae) from Southeast Asia. Zootaxa, 4032 (4), 381-394. https://doi.org/10.11646/zootaxa.4032.4.3

Tan, M. K. \& Ingrisch, S. (2013) New taxa and notes of some described species of scaly crickets (Orthoptera: Mogoplistidae: Mogoplistinae) from Singapore. Zootaxa, 3637 (1), 17-28. https://doi.org/10.11646/zootaxa.3637.1.2

Tan, M. K., Ingrisch, S., Baroga-Barbecho, J. B. \& Yap, S. A. (2019) New species of Ornebius (Orthoptera; Mogoplistidae; Mogoplistinae) from Siargao Island of the Philippines. Zootaxa, 4590 (1), 166-176. https://doi.org/10.11646/zootaxa.4590.1.7

Tan, M. K. \& Kamaruddin, K. N. (2013) New species of scaly crickets (Orthoptera: Mogoplistinae) from Bukit Fraser, Malay Peninsula. Zootaxa, 3721 (3), 258-264. https://doi.org/10.11646/zootaxa.3721.3.2

Tan, M. K. \& Wahab, R. A. (2018) Preliminary study on the diversity of Orthoptera from Kuala Belalong Field Studies Centre, Brunei Darussalam, Borneo. Journal of Orthoptera Research, 27 (2), 119-142. https://doi.org/10.3897/jor.27.24152

Tan, M. K., Yeo, H. \& Lee, J. X. Q. (2015) Diversity of entomofauna (Orthoptera, Reduviidae and Aculeata) in the Mandai-Lake Road area, Singapore. Nature in Singapore, 8, 37-51.

\section{Figure captions}




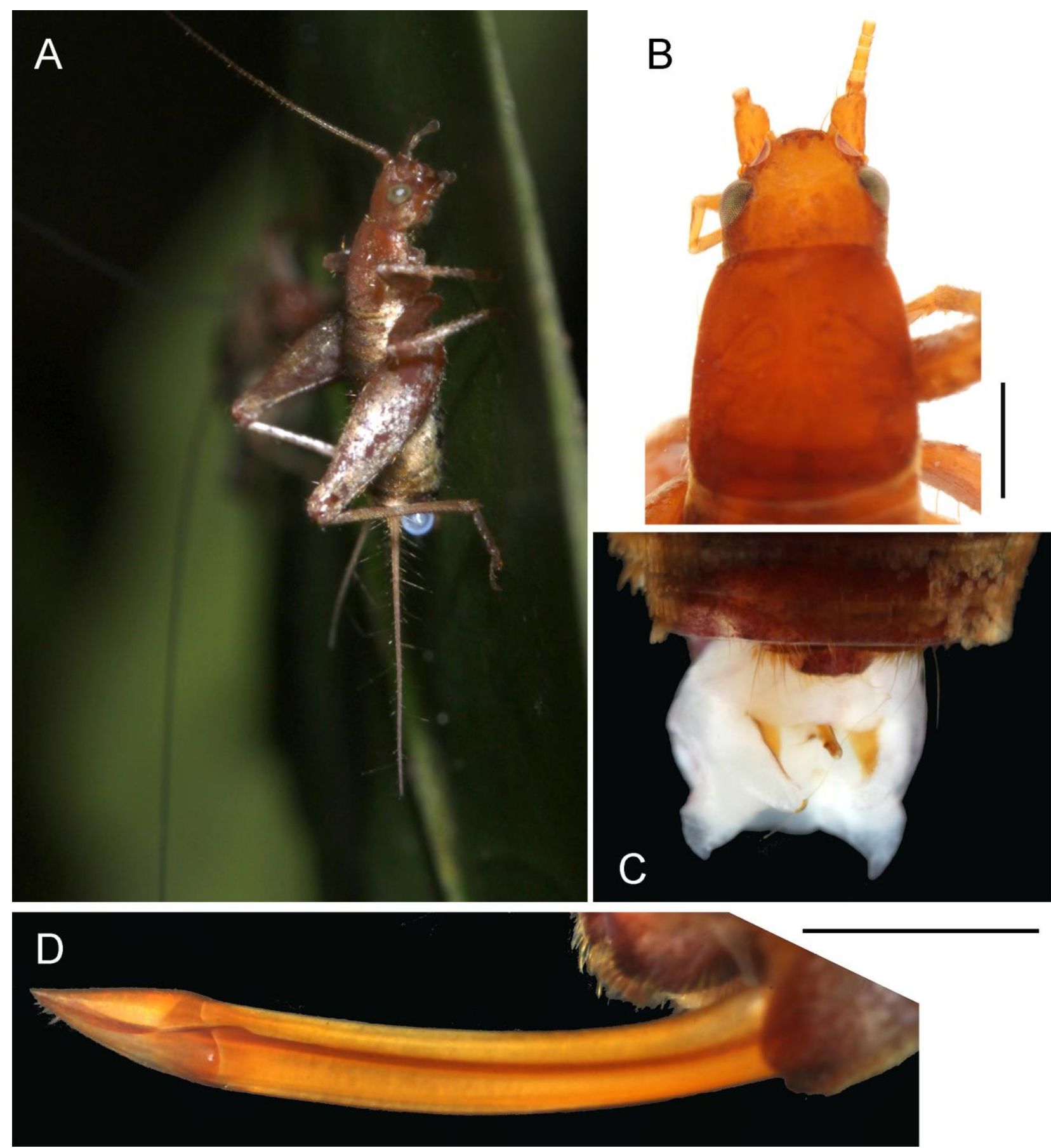

FIGURE 1. Apterornebius kinabalu Ingrisch, 2006 male with spermatophore on a foliage (a female can also be seen in the background) in Kabili Sepilok Forest Reserve, Sandakan (A); in ethanol, male head and pronotum in dorsal view (B), male abdominal apex in dorso-lateral view (C) and ovipositor in lateral view (D). Scale bar: 1 $\mathrm{mm}$. 

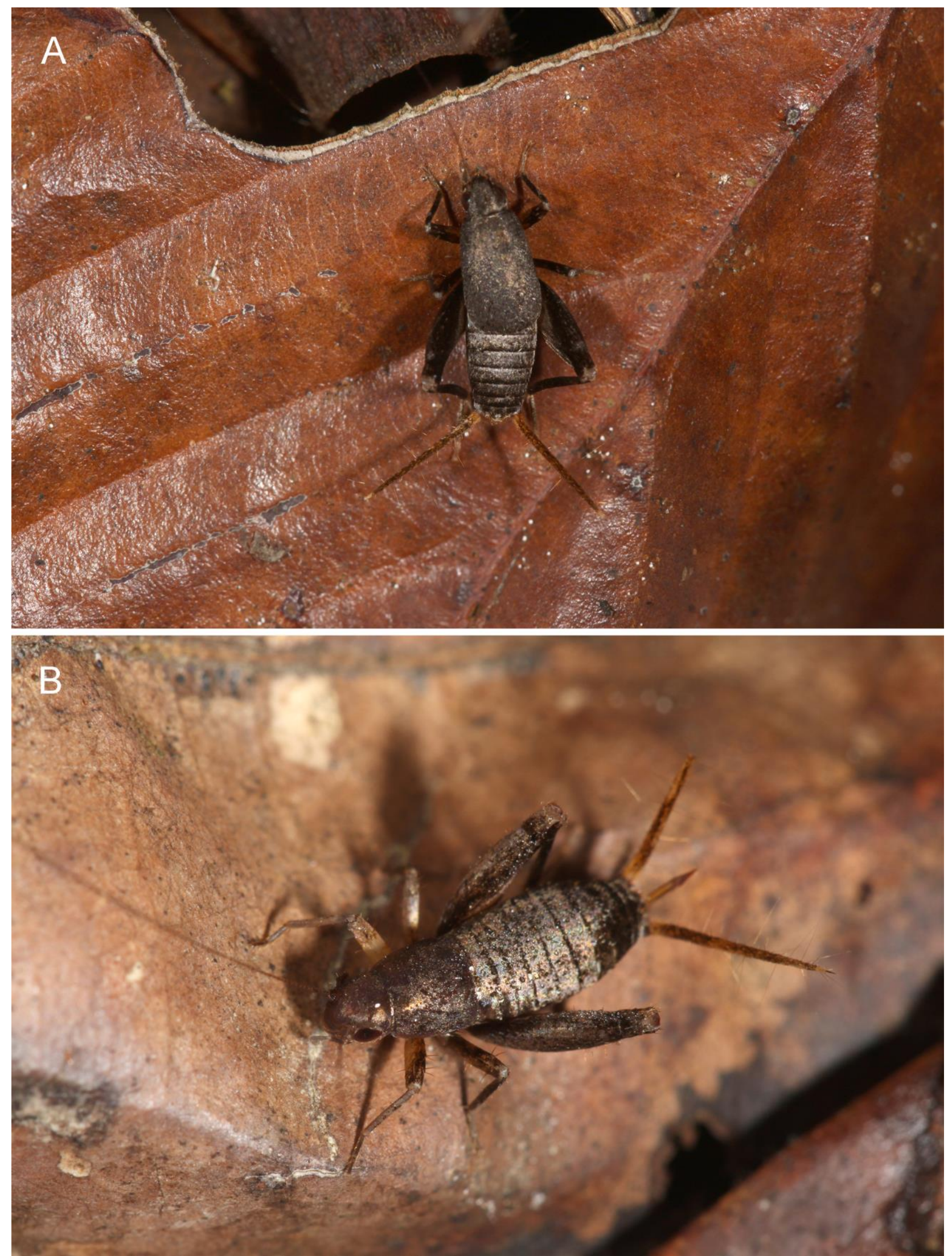

FIGURE 2. Cycloptiloides bimaculata Tan, Razy, Chung \& Ingrisch, sp. nov. male (A) and female (B) adults on leaf litters in Rainforest Discovery Centre, Sandakan. 


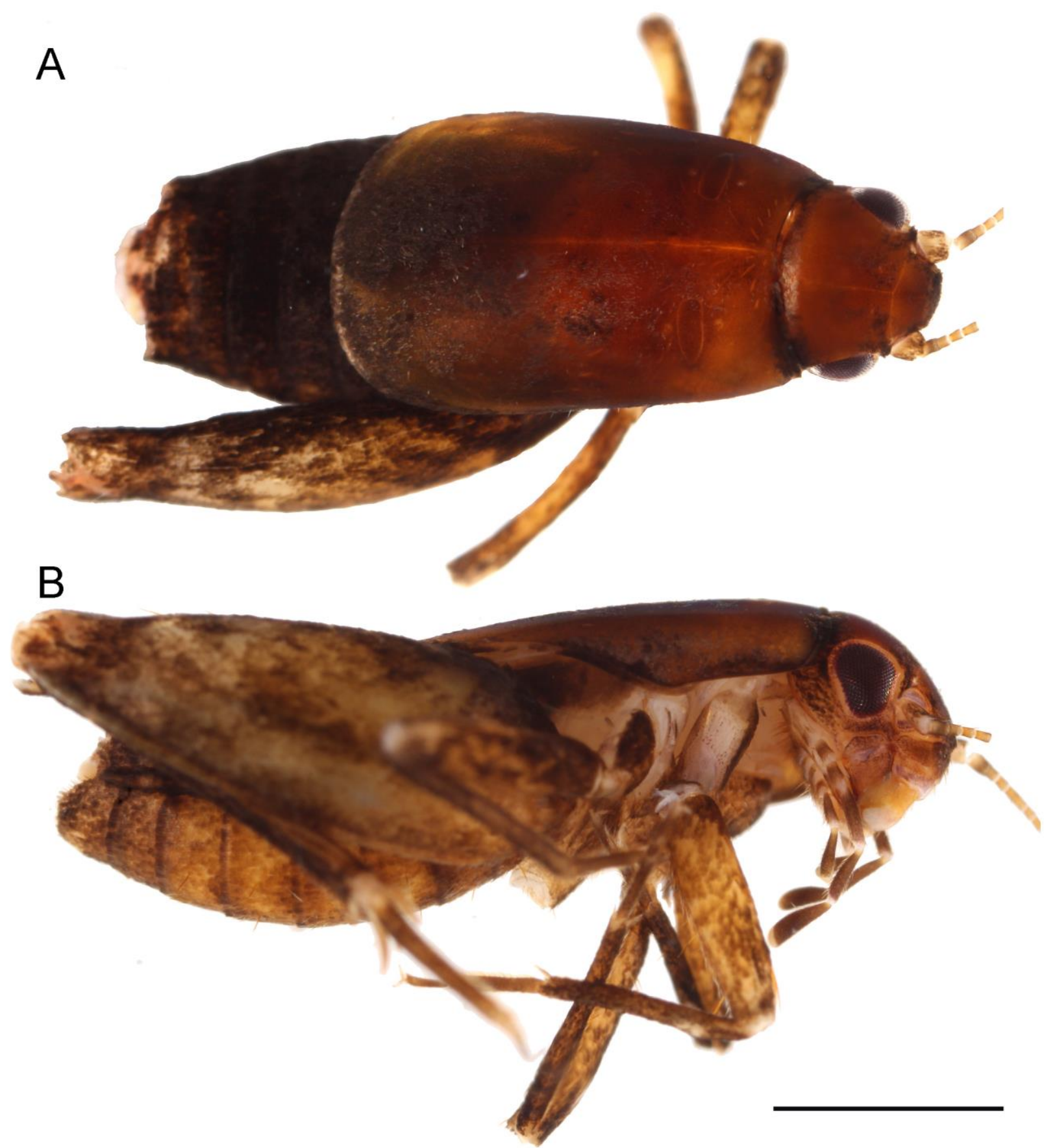

FIGURE 3. Cycloptiloides bimaculata Tan, Razy, Chung \& Ingrisch, sp. nov. male holotype habitus in ethanol in dorsal (A) and lateral (B) views. Scale bar: $1 \mathrm{~mm}$. 
A
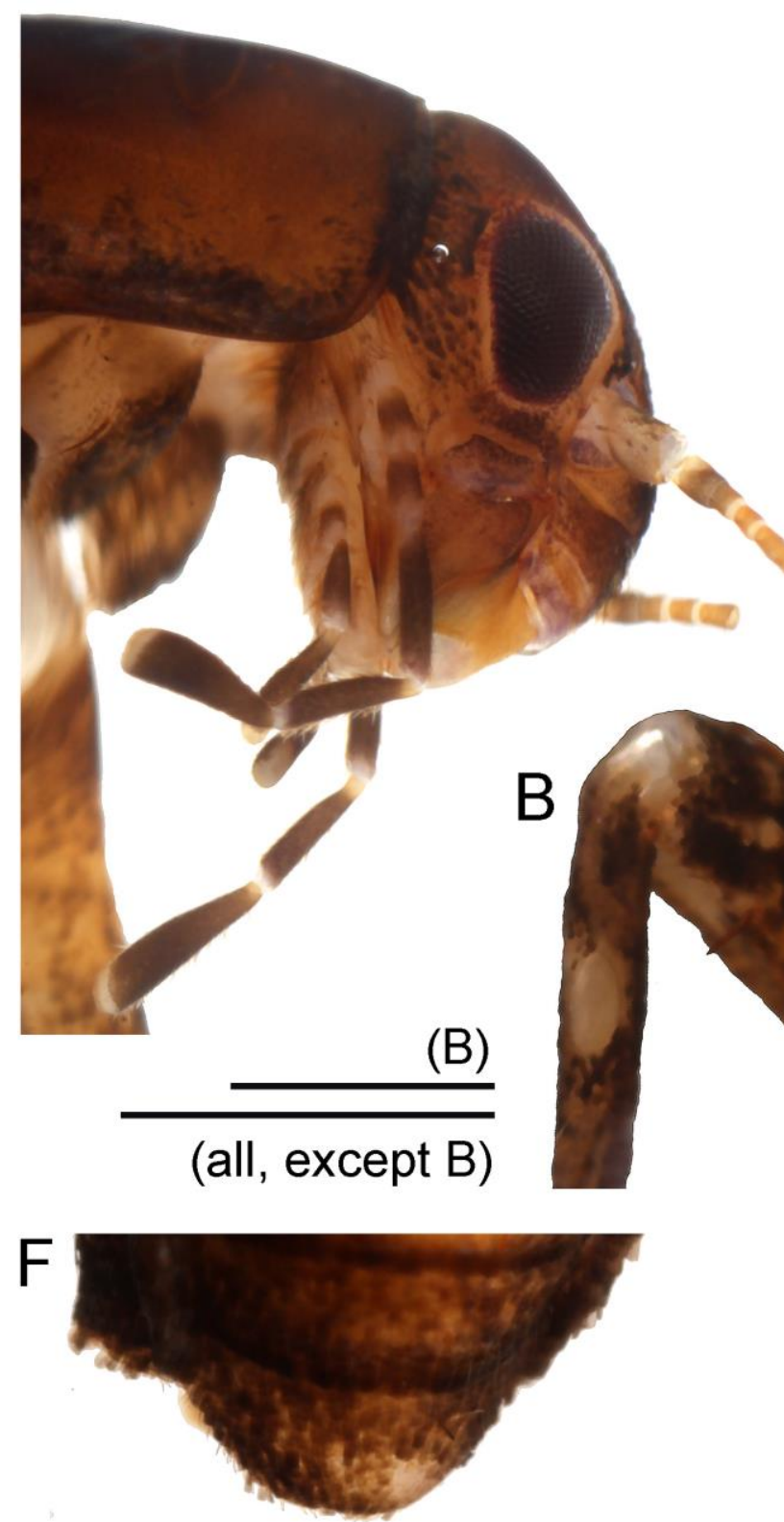

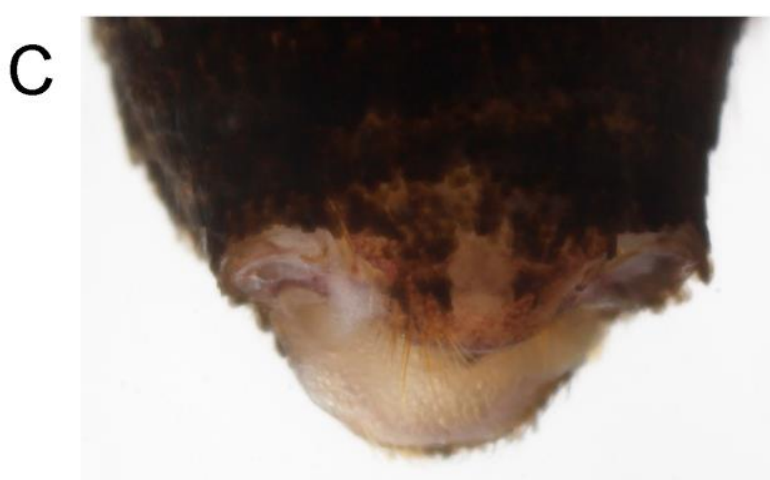

$\mathrm{D}$

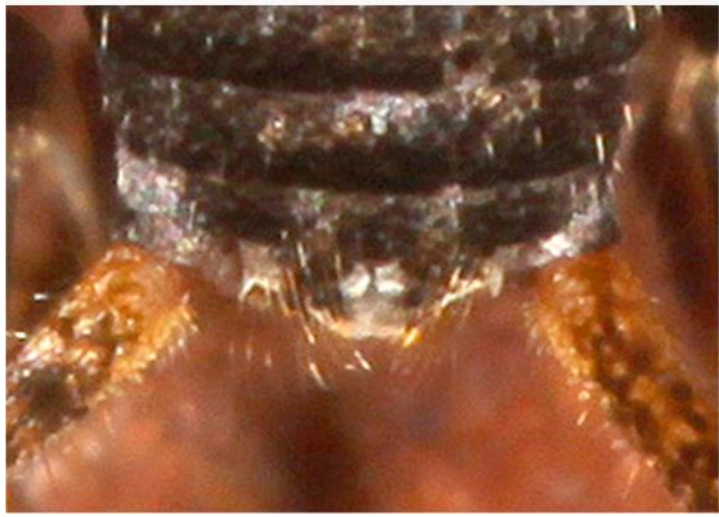

$\mathrm{E}$

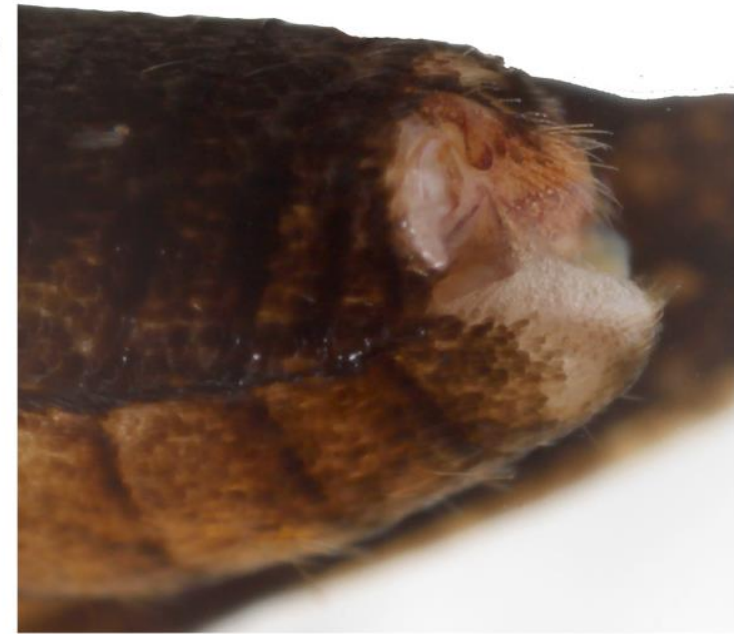

FIGURE 4. Cycloptiloides bimaculata Tan, Razy, Chung \& Ingrisch, sp. nov. male holotype: head (A) and inner tympanum (B) in lateral view; male abdominal apex in dorsal ( $\mathrm{C}$ in ethanol, $\mathrm{D}$ from live photograph), lateral (E) and ventral (F) views. Scale bars: $1 \mathrm{~mm}$ (all except B), $0.5 \mathrm{~mm}(\mathrm{~B})$. 


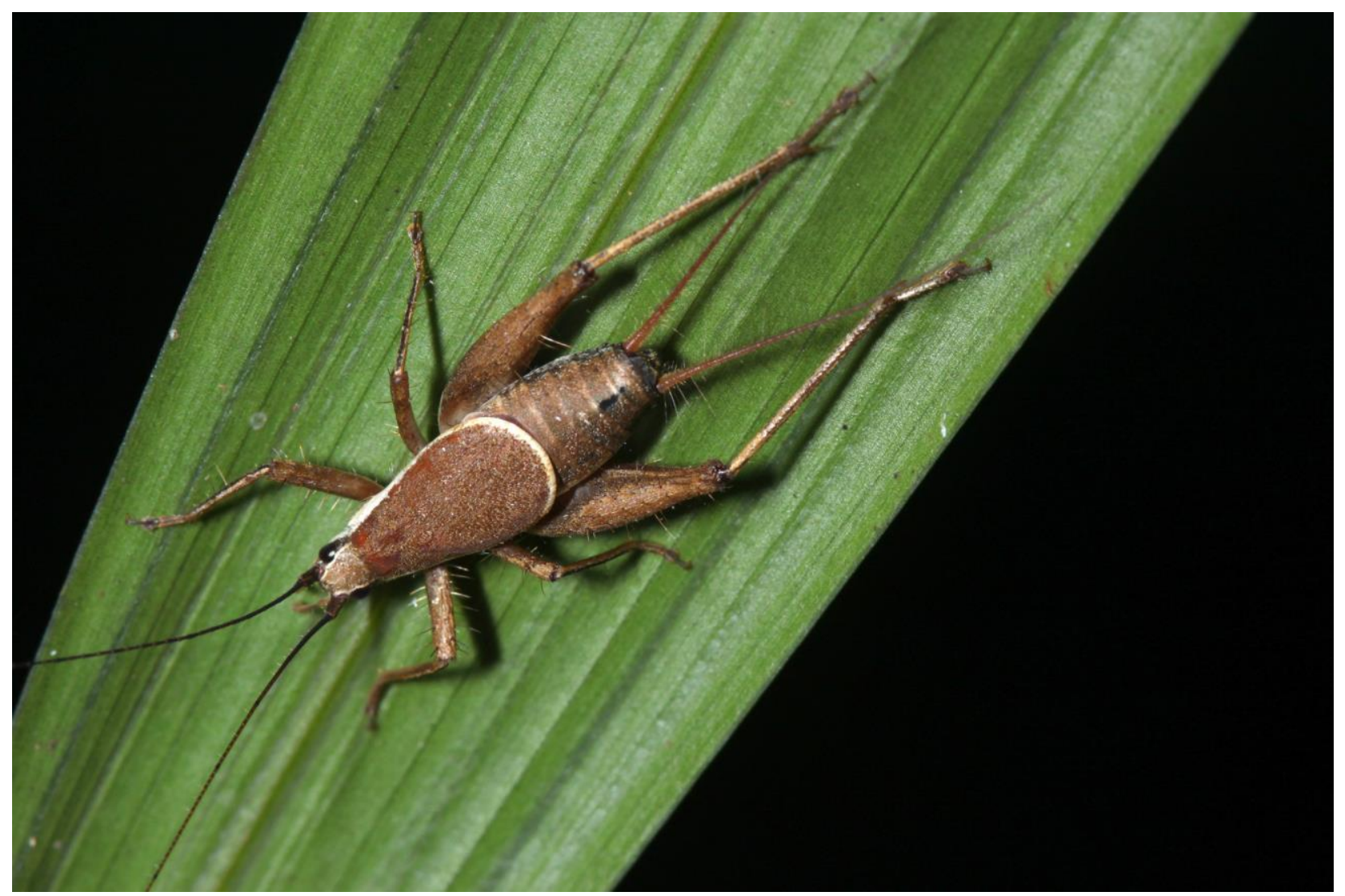

FIGURE 5. Ectatoderus nigrofasciatus Tan \& Wahab, sp. nov. male holotype on a palm/ rattan leaf in Belait. 

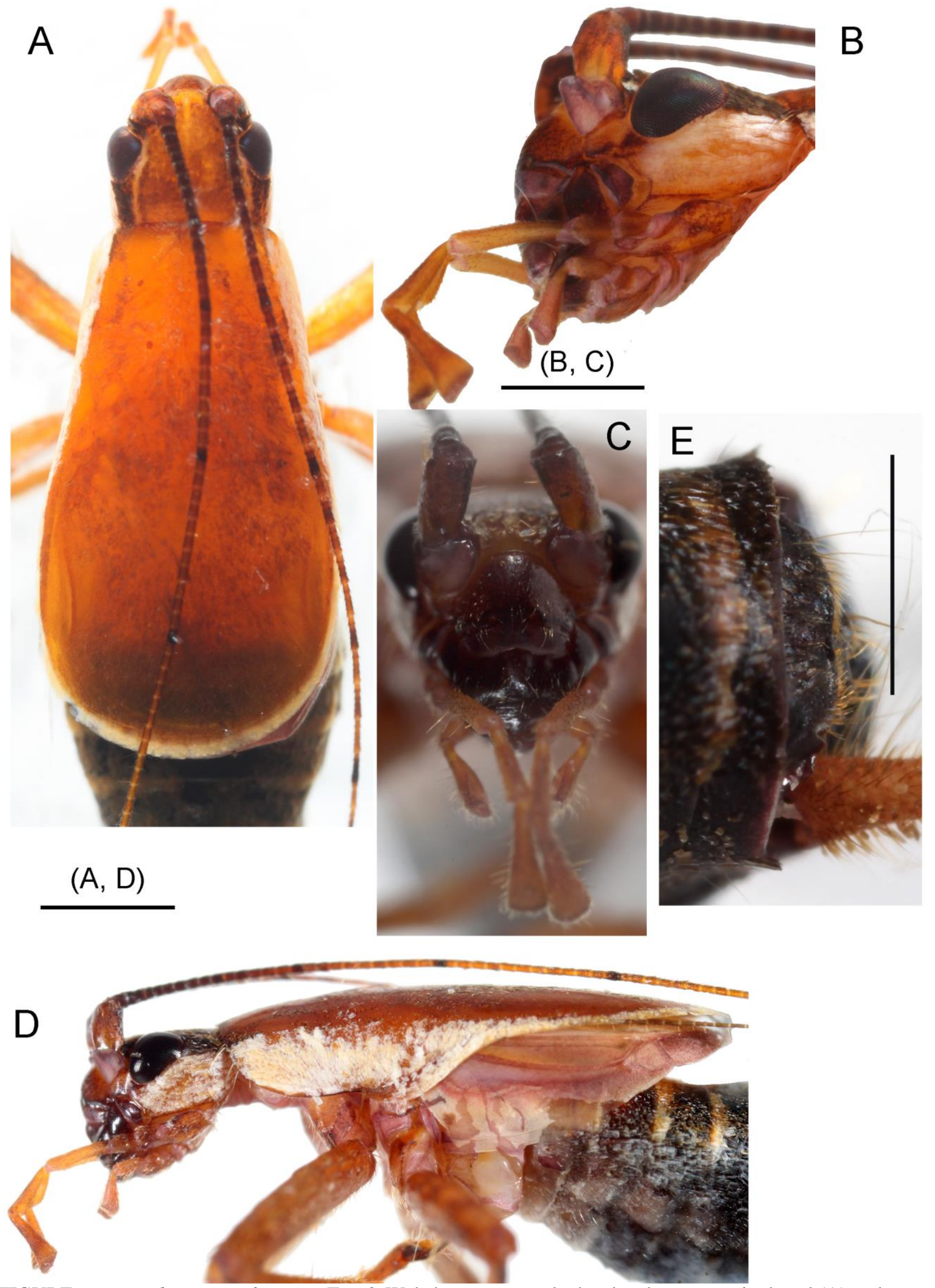

FIGURE 6. Ectatoderus nigrofasciatus Tan \& Wahab, sp. nov. male: head and pronotum in dorsal (A) and lateral (D) views, head in lateral (B) and anterior (C) views. Scale bars: $1 \mathrm{~mm}$. 


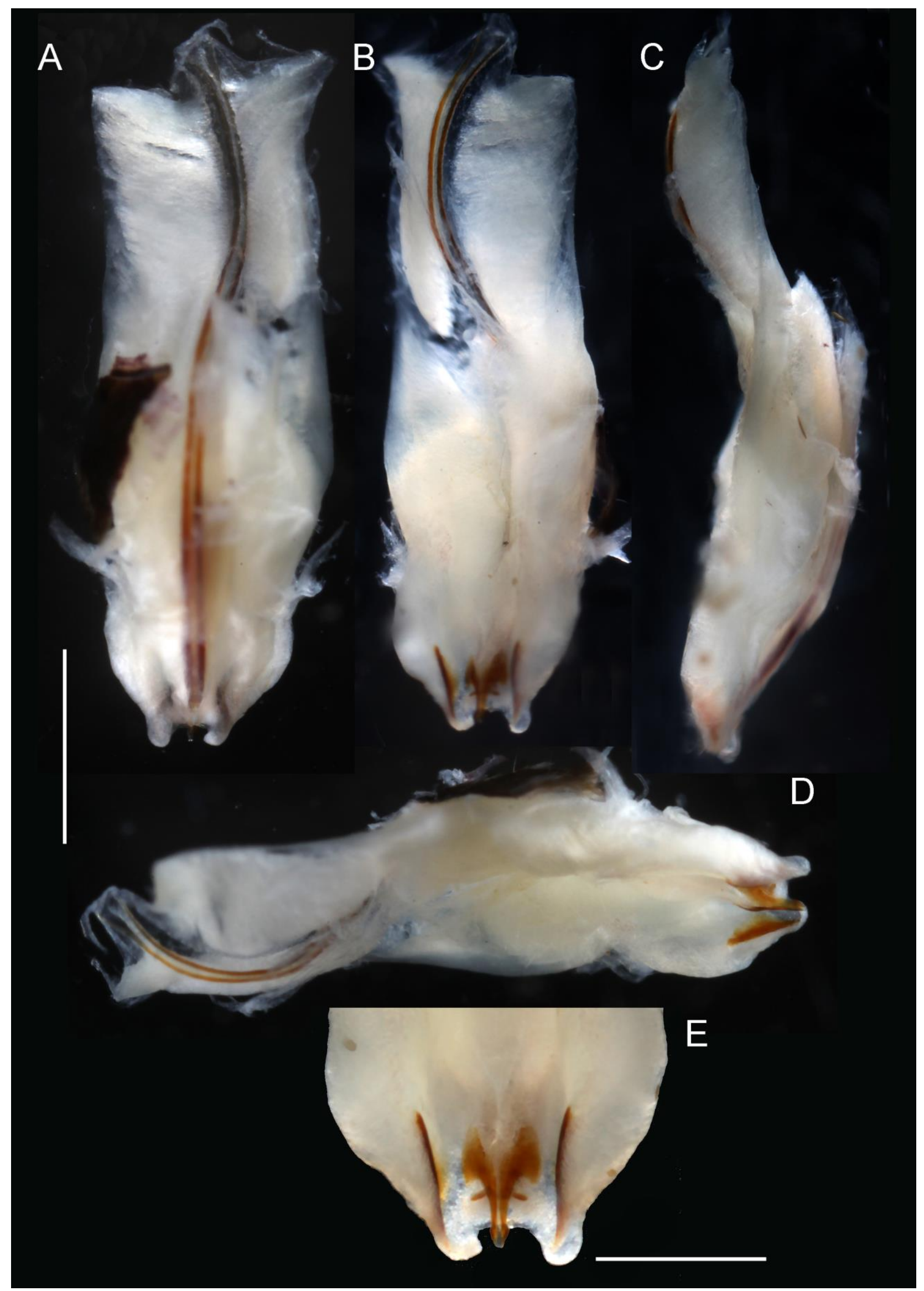

FIGURE 7. Ectatoderus male phallic complex: Ectatoderus nigrofasciatus Tan \& Wahab, sp. nov. in dorsal (A), ventral (B), lateral (C) and latero-ventral (D) views; and apex of medial valve in ventral view (E). Scale bars: $1 \mathrm{~mm}(\mathrm{~A}-\mathrm{D}), 0.5 \mathrm{~mm}(\mathrm{E})$. 

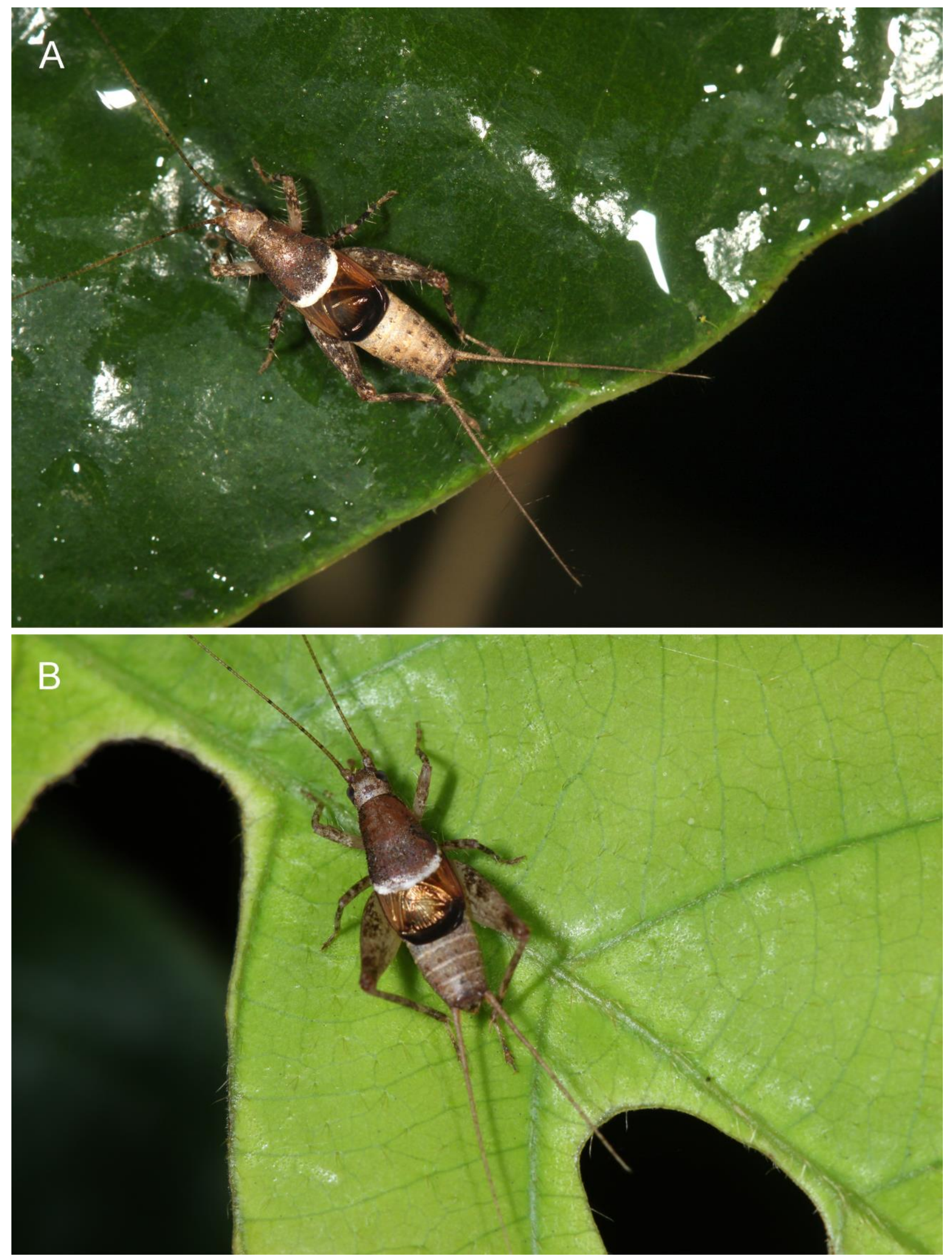

FIGURE 8. Ornebius pullus Ingrisch, 2006 males in their natural habitats in Belait: BRU.19.13 (A) BRU.19.74 (B). 

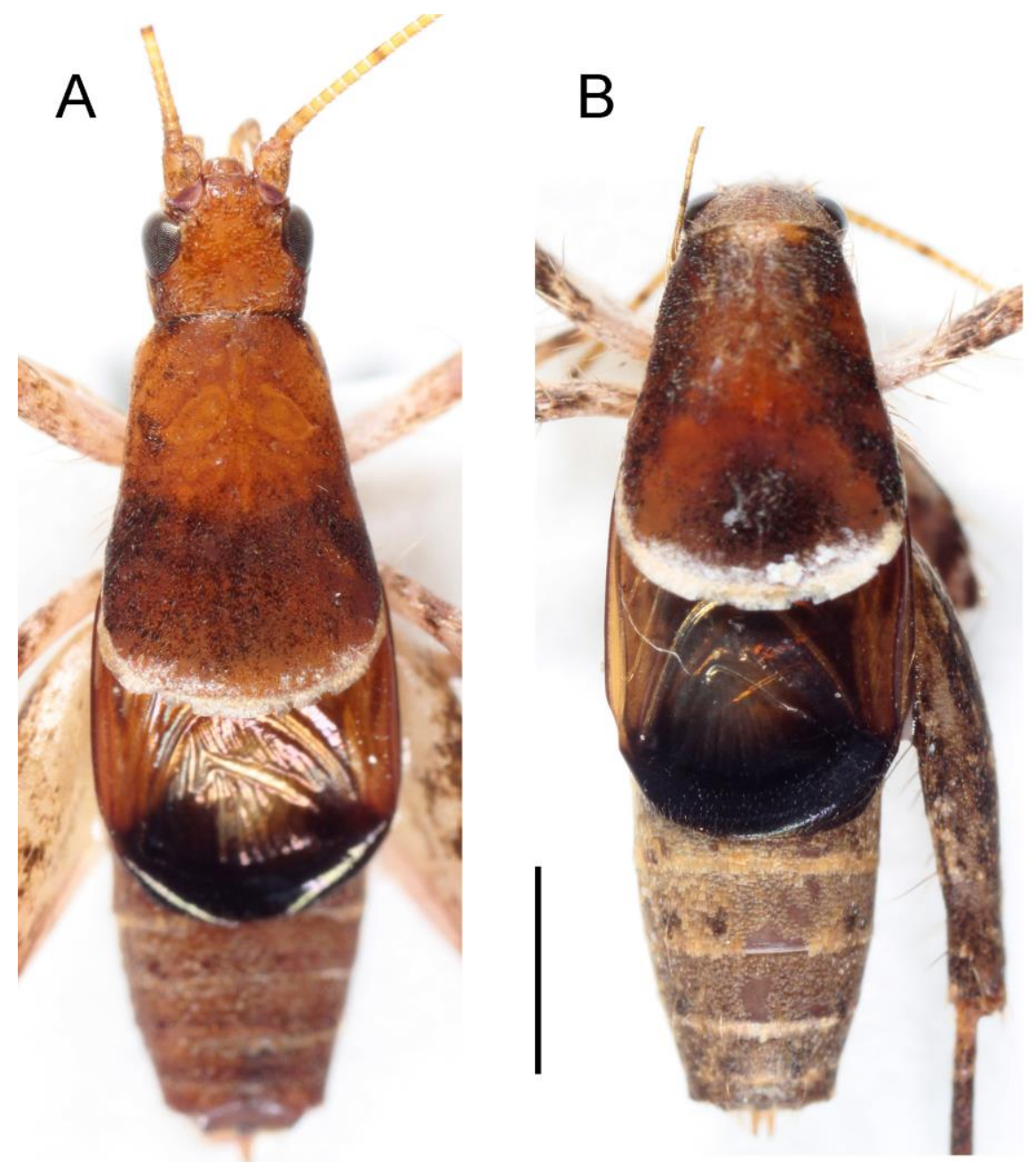

\section{C}

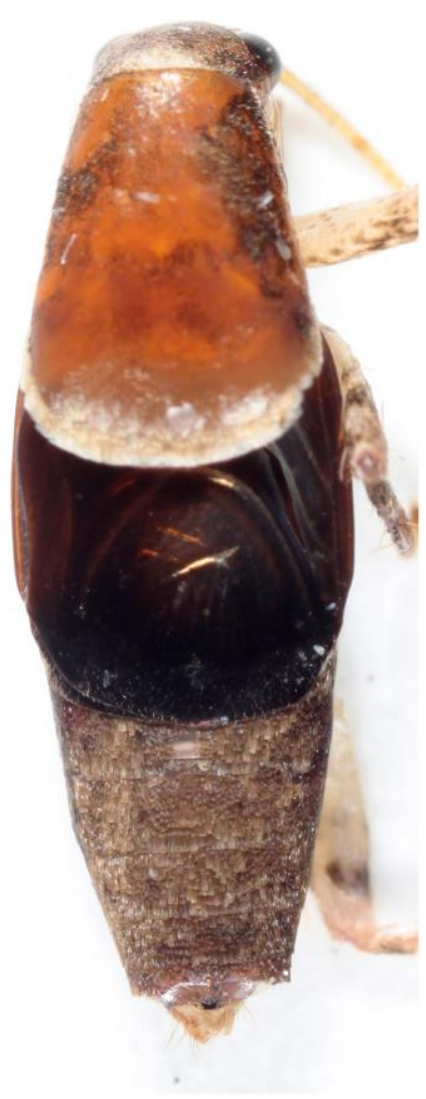

FIGURE 9. Ornebius pullus Ingrisch, 2006 male habitus in dorsal view: Belait (A, B) and Singapore (C). Scale bar: $1 \mathrm{~mm}$. 

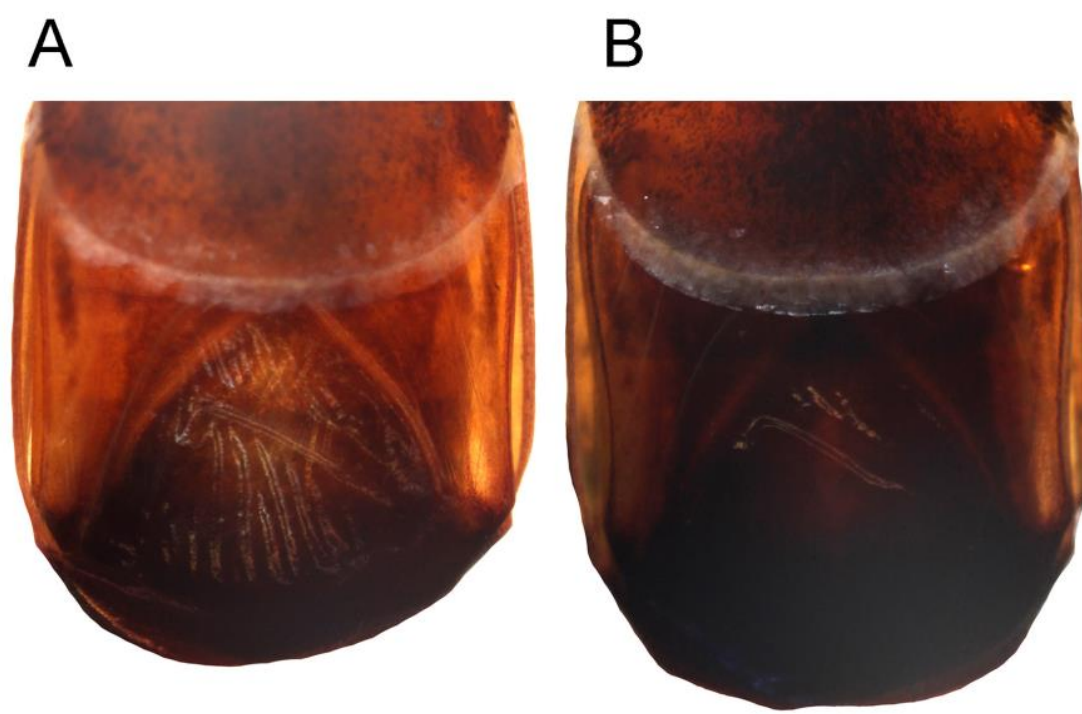

C
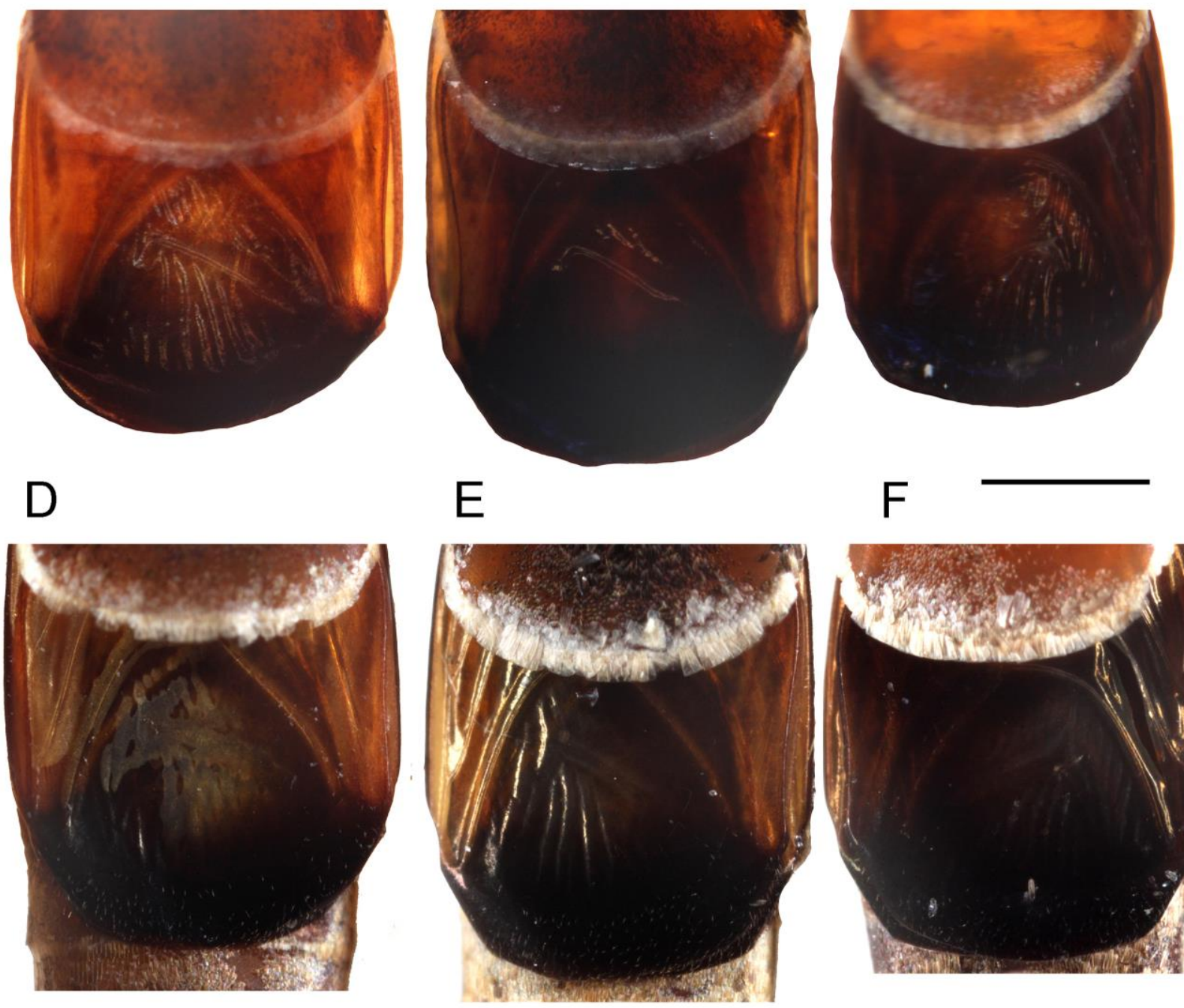

\section{G}
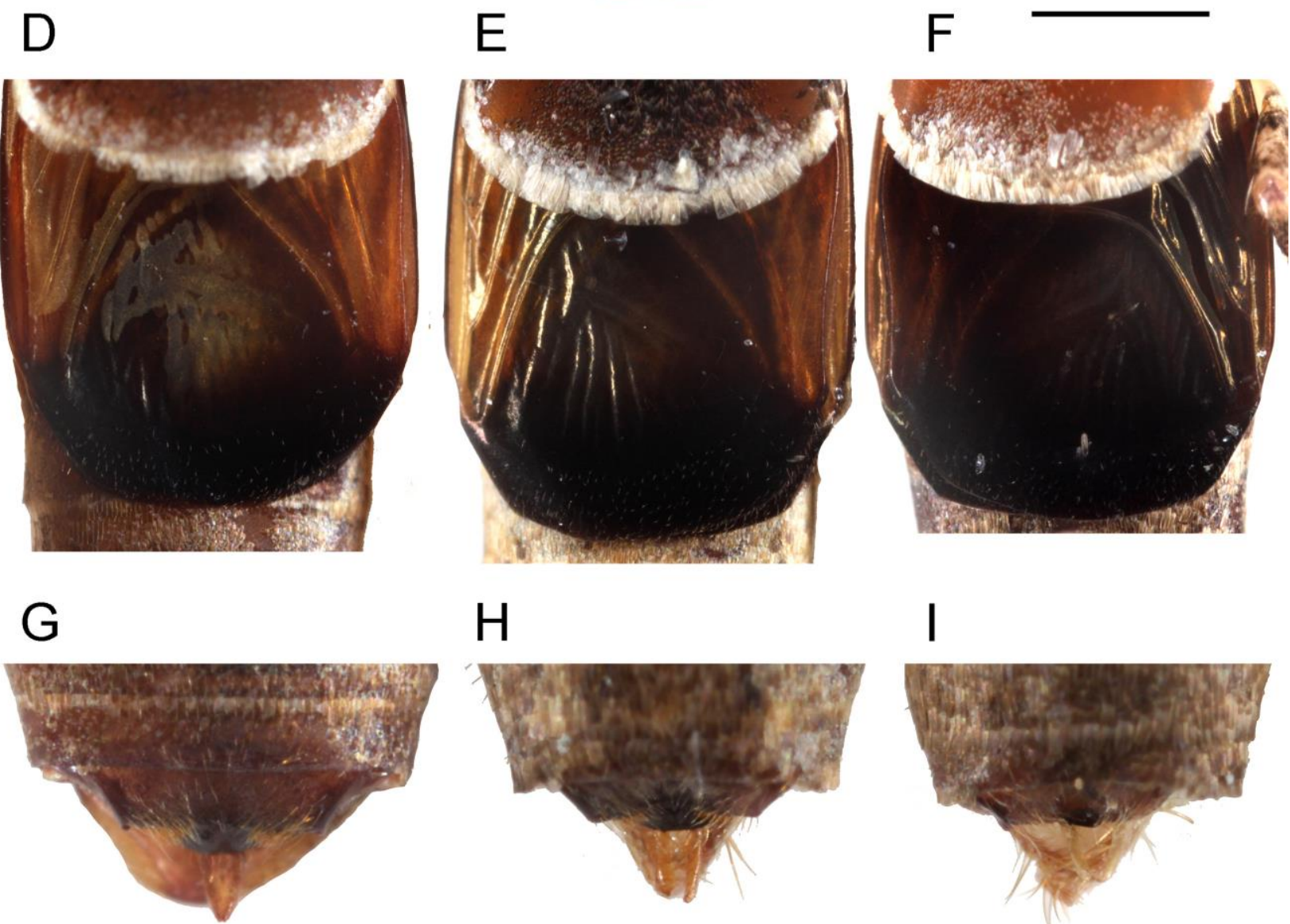

FIGURE 10. Ornebius pullus Ingrisch, 2006 male tegmen in ethanol (A-C) and dried-preserved (D-F) and male abdominal apex (G-I) in dorsal views: Belait (A, B, D, E, G, H) and Singapore (C, F, I). Scale bars: 1 $\mathrm{mm}$. 